\title{
Scales of sustain and decay: making music in deep time
}

\section{PHILIPP KOHL}

Department of Slavic Languages and Literatures, Ludwig Maximilian University of Munich, Schellingstr 33, 80799 Munich, Germany

philipp.kohl@lmu.de

\begin{abstract}
This article explores the relationship between the human time of music making and the temporal layers that pervade the natural resources of musical instruments. It therefore offers case studies on two of popular music's most common instruments, the electric guitar and the synthesiser, and their symbolic and material temporalities: guitar players' quest for 'infinite sustain' from Santana to today's effects manufacturers and the 'psychogeophysical' approach by artist and theorist Martin Howse, who developed a synthesiser module using radioactive material in order to determine musical events by nuclear decay. While language uses metaphors of sustain and decay as figurative ways to express both musical and planetary dimensions, practices of music offer alternative ecologies of relating the seemingly unrelatable scales of deep time and musical time. If in the Anthropocene humankind becomes aware of its role as a geophysical force, thinking about making music in the Anthropocene requires an awareness for the temporalities involved in the materials at hand. Besides an ecological perspective, the article looks at various media (magazines, ads, and manuals) and thus positions economical mechanisms of the musical instrument manufacturing market as a small-scale experimental setting for larger-scale industrial processes.
\end{abstract}

We are stardust, we are golden

We are billion year old carbon And we got to get ourselves back to the garden ${ }^{1}$

\section{Introduction}

In Tom McCarthy's 2015 novel Satin Island, the first-person narrator cannot stop watching online footage of oil spills. He imagines a talk he is supposed to give at a conference, coming back to his favourite subject:

When oil spills, Earth opens its archives. That it takes the form of vinyl when it hardens is no chance occurrence; what those men in body-suits on beaches should be doing is not brushing it away but lowering a needle to its furrows and replaying it all, and amplifying it all the while to boot: up and up, exponentially, until from littoral to plain to mountain, land to sky and back to sea again, the destiny of every trilobite resounds. (McCarthy 2015, p. 118)

${ }^{1}$ Joni Mitchell, 'Woodstock', Ladies of the Canyon. 
McCarthy's vision goes far beyond aestheticising human-made catastrophes. It is a vision of media and music history on a fossil scale, a scale that has become all the more dominant since the rise of oil as a master resource of industrial production. A configuration Stephanie LeMenager calls 'petromodernity' (LeMenager 2014) has been described as a decisive factor for music production and distribution (Devine 2015). Since records ceased to be made from shellac based on secretions of living insects, popular music has become dependent on fossil resources (Smith 2015). It continues to do so in the digital age, where microprocessors and LCD displays add two material temporalities: the age of rare earth mineral resources and the microscopic timespans of electronic processes. From this point of view, Earth not only opens its archives on the disastrous occasions of oil spills, but every time a track of music is played or streamed: continuously. Tracking the material archives of media is a perspective various studies have been pursuing under the term 'media archeology' for quite some time. Yet a few years ago the discipline ventured back further in time. While Siegfried Zielinski in his book Deep Time of the Media (Zielinski 2006) applies ideas from geological and paleontological historiography of nature to human media history metaphorically, Jussi Parikka in A Geology of Media asks for the importance of the nonorganic in constructing media before they become media: the literal deep times and deep places of media in mines and rare earth minerals' (Parikka 2015, p. 5). In popular music, there is, however, another level of materiality that deserves more attention: that of instruments. When McCarthy imagines a disc of oil to be played with a needle - does 'playing' it mean to make music or to merely reproduce something? This article will look at playing musical instruments in the Anthropocene precisely from this point of view. Playing sounds on things with their material, non-human temporalities affects the very question of mimesis. Seen this way, the acts of picking a string on an electric guitar and tweaking a knob of an analogue synthesiser constitute not only moments of musical creation but also mediated sonifications of distant, non-human pasts.

To get a hold of the temporalities that pervade musical instruments, their materials and players, I will have a closer look at two of popular music's main instruments: the electric guitar and the synthesiser. I am less interested in their stylistic features and popular images than the materials they are made from and the sounds they are made for. Writing about sustain and decay, this article makes use of ambivalent temporal metaphors: these words denote not only phases of an acoustic envelope (which is commonly described with the four-part abbreviation ADSR - attack, decay, sustain, release), but also temporal categories of ecological and political dimensions. The connection between musical and planetary time drawn here seems arbitrary: 'Sustainability' in its meaning of a long-term ecological horizon is a borrowing from German Nachhaltigkeit and has little in common with musical sustain (borrowed from Italian sostenuto). ${ }^{2}$ However, in the case of electric guitarists' quest for infinite sustain, which will be the first part's subject matter, there is a deeper link. Undertaking the technical endeavour to produce a never-ending note that exceeds the affordances of a stringed instrument, guitar makers and players drive the boundaries of the electric guitar towards the electronic - and thus extend the material temporalities of the instrument.

\footnotetext{
${ }^{2}$ On the history of the term sustainability see Du Pisani (2006).
} 
In the second part, I will examine one artistic attempt to transcend the metaphor of decay as a category of musical time towards deep time: Martin Howse's Earth Return Distortion modules, which use soil and radioactive minerals as a source of modulation and their poetic manuals that ironically confront users with the nonhuman timescale of the materials at hand - decaying isotopes that require a replacement in several billion years. As noted before, the deep time of the planet is very different from musical time. It is a timespan so vast that it can neither be heard, seen nor imagined. Yet it is the time proper to the materials on which music is made - and thus an issue the Anthropocene debate has drawn attention to. If the term Anthropocene marks humankind's awareness of being a geophysical force on a planetary scale (Morton 2016, p. 9), it confronts time regimes incompatible with each other. ${ }^{3}$ This article will not raise ethical or political questions about whether resources used for instruments are sustainable or not, but rather explore the temporal scales invisibly and inaudibly involved in music making to approach the very concept of sustainability.

My approach is only partly new. Concepts of spatial and temporal 'depth' have been crucial to musical thought since early Romanticism (Watkins 2011). In his writings on music, German romanticist E.T.A. Hoffmann likens the composer's work to an imposing tree that makes people wonder how it came to grow in such a way. The task of the critic is then

to let the people see into the depths of the earth, as through crystal, so that they discover the seed, and realise that from this very seed the entire tree sprang. Indeed they will see that tree, leaf, blossom, and fruit could take only that form and colour and no other. ${ }^{4}$

What Hoffmann takes as a metaphor for music perception, conceptual music literally does. In his book Earth Sound, Earth Signal, Douglas Kahn has described how 20th-century composers make use of Earth sounds (Kahn 2013). Since the 2010s, a group of artists, programmers, musicians and media theorists have been investigating the Earth and the present perception under the term 'psychogeophysics'. This approach plays a crucial role for Martin Howse's synthesiser designs discussed in the final section. As the choice of material suggests, I will understand music making as a practice entailing a wide range of social forms, ranging from mass consumption and DIY culture to conceptual art.

\section{Infinite sustain, finite sustainability}

The electric guitar is a product of petromodernity like no other popular instrument. Leo Fender's concepts for the first mass-produced instrument in the late 1940s were influenced by processes of the automotive industry. His biggest-selling models are named the Telecaster and the Stratocaster. Reaching 'far' and 'spreading' out ('stratum' going back to the root for 'to spread') are these name's self-fulfilling prophecies having a planet-encompassing impact as a new, mass-produced species of the instrument. Needless to say, the impact of guitar-making is not a geological one. In contrast

${ }^{3}$ For a historicising overview of how authors have been neglecting geological time as an indispensable problem of the Anthropocene debate and an overview of human and non-human timescales to think of, see Chakrabarty (2018).

${ }^{4}$ Hoffmann, E.T.A. (1989[1820]), p. 426. On the ecological dimensions of his musical thought, see Watkins (2011, pp. 44-8). 
to music distribution and live events, the production of musical instruments with their comparably tiny market volume has never been and will never be an ecological factor in numerical terms. The iconography of the electric guitar, however, is deeply petrocentric. This feature is both emblematised and ridiculed in Mark Ryden's cover illustration for the 1989 album Jeff Beck's Guitar Shop. The picture shows a car-sized Stratocaster in Beck's signature colour being repaired in a 1950s garage. Beck is known to collect vintage cars and has previously posed with a convertible for an amplifier ad, alluding to the 'convertibility' of the company's heads and boxes. ${ }^{5}$ Whereas many manufacturers use the obvious analogies between automotive and aeronautical imagery and instruments in their advertising, ${ }^{6}$ Beck's guitar appears to be out of service. The album's entry song, 'Guitar shop', is a spoken-word guitar ad featuring drummer Terry Bozzio, pitching real and surreal features ('Pre-amp pro sound performance/Groove tube/Killer caps/You're a strap cat/Patch in/Dangerous distortion/Serious sustain'), ${ }^{7}$ accompanied by an instrumental stylisation of the noodling sounds typical of a guitar store ambience. On track 7, 'A Day in the House', Bozzio mocks environmentalist parliament addresses ('We must strike out and rescue this/Fine earth upon which we live/Mother nature as suffered far too long and quite enough/What's she been said my lords/Nothing is being done'), the last line fading into monotonous repetition. ${ }^{8}$

The scope of Beck's lyrics point to a paradoxical situation of the electric guitar as a product of petromodernity: as an instrument with a body and hardware that needs maintenance, it is part of a chain of production and depends upon natural resources (both organic and inorganic). On a symbolic level, as the major instrument of post-war popular music, it can be seen as an embodiment of two conflicting human time regimes: presentism and the quest for immortalisation. ${ }^{9}$ On the level of sound, 'serious sustain' seems to play a major role in the longing for immortality. With the rise of effect pedals, compression and distortion effects were marketed to extend the sustain of the clean guitar tone and to allow the development of feedback techniques. The ability to create a tone that artificially transgresses the natural sustain of a note proved to be a rich source of phantasmatic images. In his book on heavy metal, Robert Walser quotes producer Reinhold Mack:

Distortion gives that feeling of ultimate power. The more distortion you get, the more satisfying it is. There's something slightly superhuman, psychologically speaking, about the sustain, the nearly endless notes. (Walser 1993, p. 42)

The use of magnetic pickups and amplification had considerably extended possible string sustain and thus created the longing for infinite sustain. In guitarist Marc Ribot's account, this quest for tonal immortalisation becomes obsessive:

5 The full-page Seymour Duncan advertisement 'Jeff's convertibles' shows Beck sitting on the wheel of a car, holding a Fender Telecaster plugged into an amplifier stack; Guitar Player (February 1986), p. 59.

6 A Peavey advertisement has the headline 'The Road Warrior', with an image of equipment next to a truck, closing with the line: 'When the gig's on the road, you can be sure if there's a breakdown ... it's the bus!' Guitar Player (June 1989), p. 7.

7 An advertisement for the Hamer Sustainiac guitar uses the copyline 'Experience serious sustain'; Guitar Player (June 1989), p. 61.

8 See Power (2011, pp. 329-345).

9 For the paradox between the awareness of death in the present and motifs of immortality see Partridge (2015). 
All guitarists fight this death, this logarithmic decline into silence, and its implied presence in every note may be one of the reasons guitars (more than bowed or wind instruments, whose notes can be sustained at will) have long been linked to sadness and despair. ... Some guitarists fight it by squeezing the last bit out of a note with vibrato. Others use the mandolin technique of picking many notes very fast, hoping no one will notice. ... Volume also works. The sound from the amp reinforces the vibrations of the strings, creating increasingly longer sustains up to the point of feedback. Still, to struggle with the decay and death of notes (in music, things decay before they die) is one thing. To try and actually win seems somehow wrong: a Faustian error. (Ribot 2000, p. 234 f.)

Seen not in a Faustian, but Freudian dilemma, it is the work of the musician to counter the guitar tone's inherent death drive. Traditionally, this is done by adding overdrive to the signal, making use of the amplifier's tendency to produce feedback. For Carlos Santana, the first musician to popularise this way of sustaining notes, this was not merely a question of technique. In her article on Santana's 'metaphysics of tone', Melinda Latour argues that the guitarist's tone production is 'based on an understanding of musical transcendence as infinite sustain' (Latour 2018, p. 225). She not only draws on his techniques of sustain production using volume knobs, amplifier settings and feedback situations, but also on his esoteric views on transcendence. What makes Santana a charismatic figure within this context is that he tries to achieve sustain within the on-board possibilities of the electric guitar, i.e. without the use of external effects except for valve distortion and feedback.

For other sustain-seeking players, the industry developed devices to artificially extend the 'natural' vibration duration of the guitar note. With the introduction of the EBow in 1969 (Figure 1), it has become possible to set strings in seemingly endless vibration using a hand-held device. ${ }^{10} \mathrm{~A}$ more recent, less popular device marketed by TC Electronic is called Aeon, symbolically aiming at downright the longest available timespan in the vocabulary of Greek thought. Several attempts to create a guitar with an electronic sustain system have failed or remained niche products, such as the Hamer Sustainiac or the Fernandes Sustainer.

The symbolic apogee of the quest to transcend sustain as a tonal feature towards super-human sustainability has been reached before, with a custom-made instrument so intricately built it could never go into mass production. It is the 'Infinite Guitar' used by U2 guitarist The Edge on the 1987 Joshua Tree album (some long notes generated this way can be heard in the intro of 'With or Without You'). Technician Michael Brook equipped a Tokai guitar with an electronic circuit that allows the guitarist to keep strings resonating without holding an external device to the string. In an interview with Guitar Player, The Edge stresses his disinterest in the technical details:

It isn't actually my idea, so I don't know if 1 should explain it fully. But it's a guitar that plays itself [laughs], You just depress the string, pluck it once, and get infinite sustain. (Nolan and Obrecht 1985, p. 66)

At this point, the fetish of infinite sustain is commodified to the point where it can be simply retrieved - and no questions are asked about the physical limitations of the devices that provide the effect. Although used by charismatic musicians, sustain

10 More intricate and less easily applicable experiments with string sustain have been explored in academic music. For an analysis of Alvin Lucier's experiments with 'infinite' piano sustain in the piece Music on a Long Thin Wire (1972) using an electromagnetically prepared piano, see Bloland (2007). 


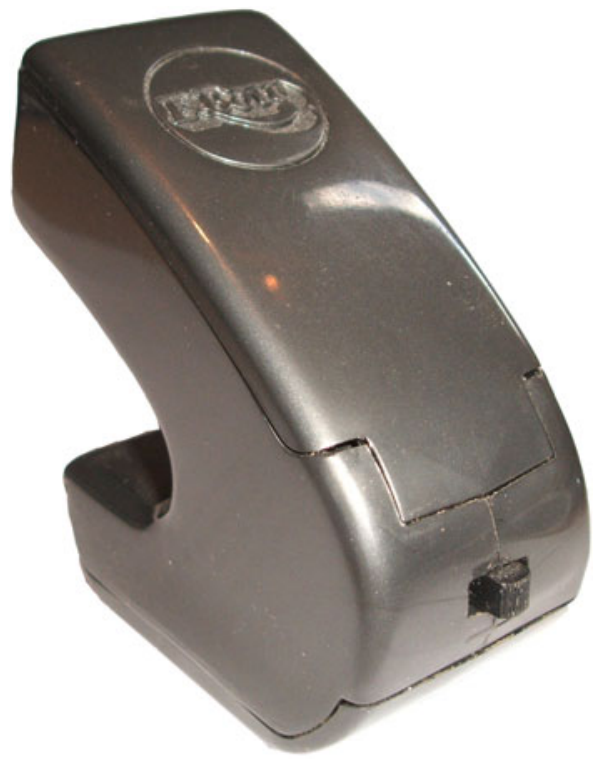

Figure 1. The EBow.

devices have remained niche products on the mass market. Sustain extension could not become an intrinsic part of the electric guitar. Its players would not accept the transformation of the electric guitar into an electronic instrument. One of the most remarkable failures in the field could be observed when a synthesiser manufacturer ventured into the guitar market: Moog's E1 guitar (2008), whose five sustain modes promise to emulate the envelope and filter possibilities of a synthesiser, including a mode providing 'infinite sustain' and one reducing the sustain to percussive strokes by artificially muting the string. An approach to sustain extension that finally succeeded on the market was not a modification to the guitar itself, but a digital effects pedal. The Freeze Sound Retainer pedal was introduced by Electro Harmonix in 2010. Based on granular synthesis, it repeats a very short portion of audio material and thus creates the impression of a motionless tone 'freeze'. ${ }^{11}$

As all of the accounts on musicians' quests for infinite sustain and the stories of their remedies betray, none of the effects are ever infinitely effective. The most accurate comment on this paradox is an effects pedal itself: the Philosopher's Tone, a compression pedal by Pigtronix (Figure 2/3). A device with philosophical aspirations, its on/off switch is labelled 'engage'. The product description reads like a parodistic manifesto:

Practitioners of the mystical and ancient art of alchemy long sought an element called the Philosopher's Stone, believing that, if found, it could turn lead into gold and bestow immortality upon the person who wielded it. The Philosopher's Tone represents an analog musical equivalent to this mythical substance in the world of guitar. ${ }^{12}$

11 Moog Music Inc. (2009, p. 1). Although not discontinued, the model is only being made upon request. More prominently, it regularly figures in articles on all-time greatest guitar flops.

12 Pigtronix (2017). Pigtronix released several editions of the compression pedal: the original Philosopher's Tone, the Philosopher's Tone Micro as well as its Germanium Gold edition, and the Philosopher's Rock. 


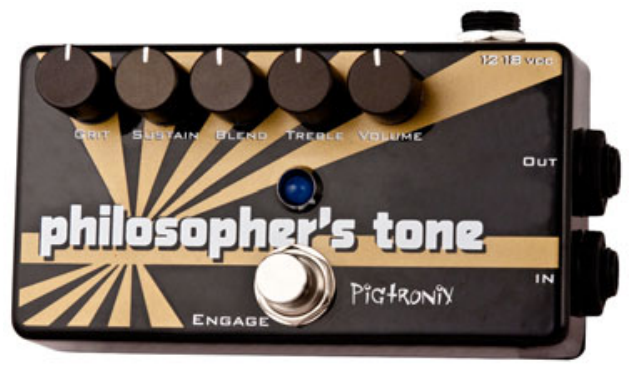

Figure 2. Pigtronix 'Philosopher's Tone', 2009.

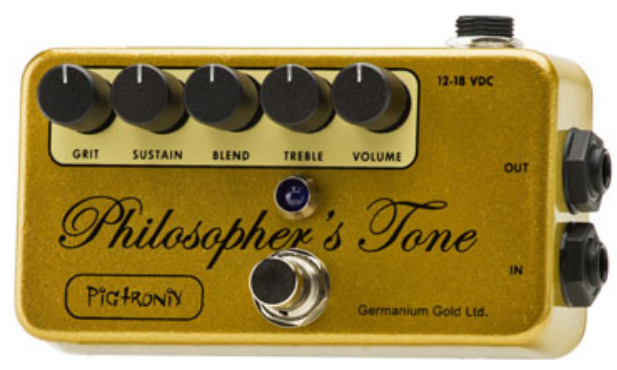

Figure 3. Pigtronix 'Philosopher's Tone' Germanium Gold Edition, 2010.

A compression pedal cannot provide 'infinite sustain' by definition - it can merely reduce the fading of the volume of a clean guitar signal. What goes beyond the alchemist metaphor of transformation is the material the effect is grounded in. In the special Germanium Gold edition of the Philosopher's Tone Micro pedal, this becomes even more striking. Before tubes were replaced with silicon transistors, germanium had been a popular material for transistors and played a seminal role in 1960s productions (Mavridis 2010). Referring to its use of germanium, the pedal alludes to an almost forgotten chapter of Earth's history in the annals of music production.

As proof of the gear community's eagerness to embrace the irreal symbolism, the Pigtronix' text quotes a blurb from Guitar Player writer Art Thompson, who elaborates upon alchemy as a popular metaphor detached from alchemist thought: ${ }^{13}$ 'People have been trying to get clean sustain from a pedal for decades, and the alchemists at Pigtronix seems to have found the secret to make it happen' (Pigtronix 2017). Alchemy and the image of the Philosopher's Stone point to a crucial problem for musical technology in the Anthropocene: that of the relationship between human action and temporalities of nature. Mircea Eliade has described this relationship with regard to premodern practices of alchemy and metallurgy:

[I]n taking upon himself the responsibility of changing Nature, man put himself in the place of Time; that which would have required millennia or aeons to 'ripen' in the depths of the earth, the metallurgist and alchemist claim to be able to achieve in a few weeks. (Eliade 1978, p. 169)

${ }^{13}$ For alchemy as a universal metaphor in post-war culture see Ziolkowski (2015). 
If the Philosopher's Tone pedal uses alchemy as an ironical allegory of musicians' desperate attempts to overcome their finiteness, this has to be situated historically in attempts to substitute time.

\section{Deep decay: Martin Howse's synthesiser modules}

This section will explore ways of making music in the Anthropocene in a very literal way: discussing synthesiser modules which use raw planetary matter as an unpredictable source of modulation. In 2015, British programmer, theorist, performer and musician Martin Howse started a series of synthesiser modules under the name Earth Return Distortion (ERD). Making them available as small-batch modules for the Eurorack system, the most common modular synthesiser format, ${ }^{14}$ Howse introduced his work into a new, popular context. While his previous work as a media artist was known among a narrow circle of international media artists and theorists, his Eurorack series became visible through electronic music media. Howse's work was brought to my own attention through Telekom's corporate publishing platform Electronic Beats that announced: 'This Modular Synth Makes Dirty Sounds Using Dirt'. As seen in the case of the Philosopher's Tone, unusual materials are regularly referred to for the sake of marketing traditional effect pedals. ${ }^{15}$ Yet in Howse's case, dirty sounds are part of a larger programme between theory and practice: psychogeophysics.

During the 2000s, Howse developed this concept together with Oswald Berthold and Wilfred Hou Je Bek, the main author of the collective manifesto What is Psychogeophysics? (The London Psychogeophysics Summit 2010). Written as a polemics against the urbanocentrism of the psychogeographic approach of the Situationists around Guy Debord, it proposes a 'novel interdisciplinary frame of psychogeophysics, colliding psychogeographics with earth science measurements and study (fictions of forensics and geophysical archaeology)'. ${ }^{16}$ Despite the accent on the material side of things, the psychogeophysical approach is a deeply literary one when it comes to the role of time. Hou Je Bek quotes various writers in the manifesto, among them Vladimir Nabokov's autobiographical novel Speak, Memory (19361951), whose narrator does 'not believe in time' but in a 'sense of oneness between sun and stone'. ${ }^{17}$ The manifesto opts for a radical outsideness of deep time as a nonhuman scale:

Time does not exist: our lives are too short to 'measure' it, time has astronomical minutes and geological seconds. Time is nonhuman. What we experience as time is background noise 300 decimals behind the comma. Our time is part of the margin of error, a fluctuation too small to spawn butterfly effects even in geological time. ${ }^{18}$

14 Since its launch in 1996 by Doepfer Musikelektronik and an increased popular interest since the 2010s, the Eurorack system is currently the modular format used by a majority of analogue synthesists.

15 A crude example would be the Berlin Wall Distortion effect, using a piece of concrete from the original site as part of the circuit (Idezem 2018).

16 The London Psychogeophysics Summit (2010). The manifesto was followed by the collectively edited Psychogeophysics Handbook in the same year, a mix between an artistic manifesto, critical anthology and technical reader.

17 Nabokov, quoted by The London Psychogeophysics Summit (2010).

18 The London Psychogeophysics Summit (2010). 
Following Robert Smithson's programmatic text A Sedimentation of the Mind, psychogeophysics explores the metaphorical and literal interpenetrations of Earth and brain - not by means of Land Art, but with the power of code. A poignantly literal approach was the Telluro-geo-psycho-modulator field trip in 2015. ${ }^{19}$ Participants were invited to feed the electromagnetic waves of forest soil into their brains, attaching interfaces to their head skin. Before that, Howse had been working on several projects under the name Earthcodes, one of which would allow a computer to be booted using the ground as a sort of natural motherboard (Parikka 2015, pp. 75-8).

The musical side of his concepts Howse showed at various festivals and installations, such as the musical performance Composting the City, Composting the Net (Riga, 2014). Media theorist and musicologist Douglas Kahn points out the analogies between composing and composting in his account in a column for The Wire magazine:

Martin Howse stood at a long table of electronics and open circuits, upon which he heaped handfuls of compost, vegetables and other scraps decomposing into soil, changing the sound. He was composing composting, cycling circuits through earth-information. After a pile had built up, he put on a glove that had small bayonet contacts on the fingers wired into the system. In the past, when musicians donned such a glove, it was to generate sound and music by gauging proximity to the body and movement of the hand, much in the same way that theremin performers re-enacted the gestures of an orchestral conductor. But Howse used the thermal dampness of the compost as a conductor of electricity, an earth circuit through which signals were fed. (Kahn 2014, p. 106)

Kahn speaks of an 'epiphany' the performance triggered for him, translating the thoughts of his book Earth Sound, Earth Signal on 20th-century composers in a contemporary context. In a chapter on Pauline Oliveros's idea of the 'sonosphere' that expands existing notions of soundscape to terrestric depths, Kahn's book offers a neologism that describes his experience at Howse's performance even more aptly: 'geophany', likewise 'deepening' the aesthetic spark of epiphany (Kahn 2013, p. 176).

With his Eurorack modules, Howse translates his concepts to the standard modular synthesiser platform. Their aim is 'to infect and contaminate the world of Eurorack with a radical, new artistic sensibility' (Howse 2019). Since 2014, Howse has made several types of modules with various editions. The basic description of the ERD Vampiric edition is part manifesto, part technical description, part intertextual play:

ERD/ERD (Earth Return Distortion) is the first and most extreme expression of the ERD philosophy, seeking to literally put the earth back into circuit with technology. All world electricity travels through the earth and nearly all electronic circuitry and devices are extracted and refined from the earth. ERD/ERD puts a small block of vampire/holy earth into the Eurorack circuit, allowing control and audio signals to be distorted and amplified as they pass through the earth block. It can be viewed in conventional terms as an earth conditioned VCA (amplification factor by knob control or CV) and distortion. Local electrical and atmospheric signals also condition the earth signal. Two jack connections are also included, optionally switching out the local earth block in favour of routing through local earth piles and forest sites. (Howse 2015a, p. 2)

19 Organised by Jonathan Kemp, circuit by Martin Howse, 2 and 3 May 2015 at Furtherfield, London. 


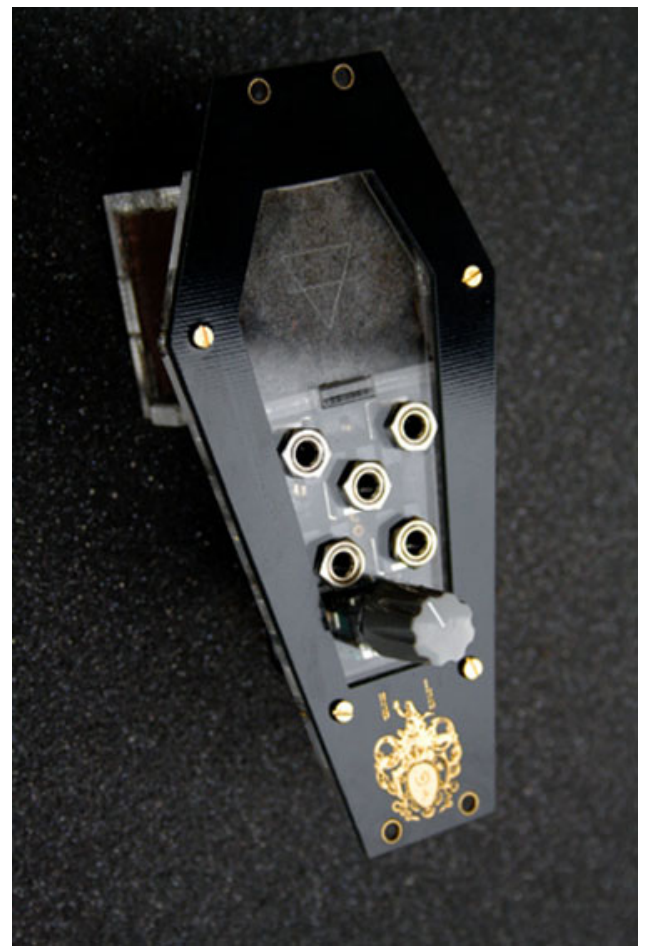

Figure 4. Martin Howse: Earth Return Distortion (ERD) Eurorack module, ERD/ERD raven edition, 2015.

As the ERD modules do not substantially do more than other sources of random modulation, I am not going to focus on their musical options but rather on the conceptual side - reading the manuals Howse published as a literary genre. The first two ERD modules (Figure 4) contain soil from sites with literary and theoretical mythologies. For the Raven edition, Howse used earth from Edgar Allen Poe's grave site in Baltimore; for the Vampiric edition, things are a bit more complicated. The manual starts with a technical disclaimer ('IMPORTANT: RED POWER CONNECTOR STRIPE/-12V IS ORIENTED TO THE BOTTOM OF MODULE'), followed by a quote from Bram Stoker's Dracula in the next paragraph (without naming the reference): 'There, in one of the great boxes, of which there were fifty in all, on a pile of newly dug earth, lay the Count!' (Stoker 1983[1897], p. 48).

Howse not only alludes to one element of Stoker's narrative - the circulation of 50 boxes with soil in London - but also to Friedrich Kittler's reading in 'Dracula's legacy' (1982). In his translation of the earth box from a textual device to a musical instrument, Howse goes even deeper. It comes as little surprise that the composition of the soil matter is determined by Stoker's text as well. Narrator Jonathan Harker proposes what Kittler calls '[h]ygienic measures of geo-political importance' (Kittler 1997, p. 75) in order to neutralise vampiric activity:

We must sterilise this earth, so sacred of holy memories, that he has brought from far distant land for such fell use. He has chosen this earth because it has been holy. Thus we defeat him with his own weapon, for we make it more holy still. (Stoker 1983[1897], p. 274) 


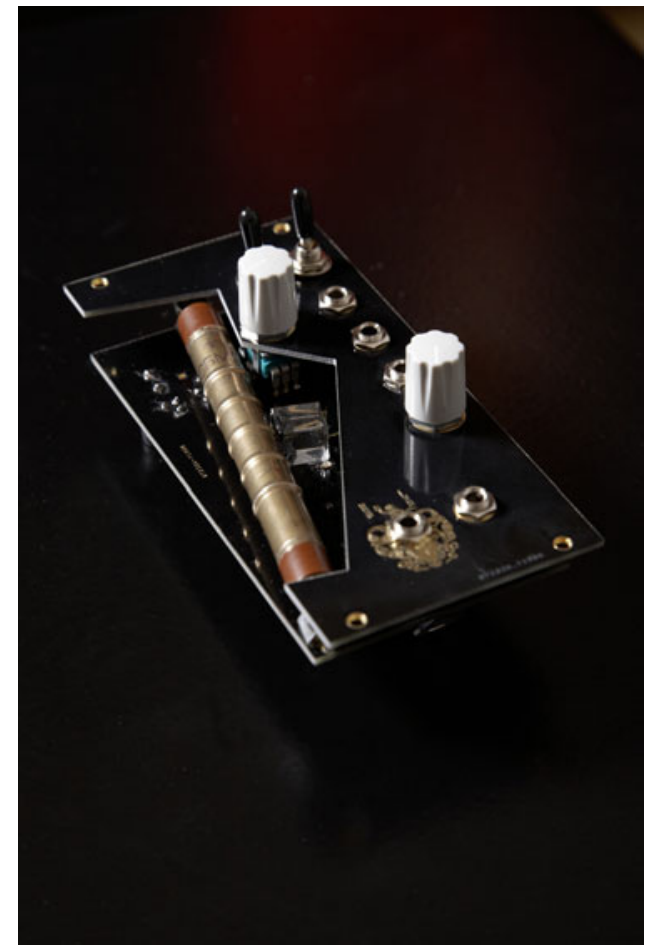

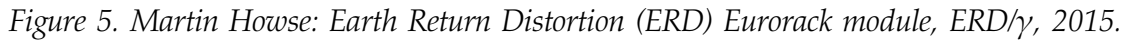

Correspondingly, the capsule

contains mixed earth from both Golgotha, Jerusalem and Whitby Abbey, England. Whitby is the landing and stranding place of Dracula's ghost ship Demeter, delivering the fifty oblong boxes ('a number of great wooden boxes filled with mould') which find their way to the Count's chapel at Carfax. This earth is essential to Dracula, it forms 'his earthhome, his coffin-home, his hell-home ...'. (Howse 2015a, p. 2)

After the dialogic introduction between Stoker's novel and Howse's module, the manual finally gives hands-on instructions. At the very end the buyer learns that the coffin-shaped modules come in a limited edition of precisely 50 which now circulate among modular users. The manual encourages its reader to connect local earth piles instead of the pre-installed, mythologically loaded dirt box.

In terms of deep time, the literary ERD editions remain on the organic surface of soil. The vampiric edition, for instance, ignores the historicity of soil, assuming that the matter from Stoker's time ('this earth') was the same as the one collected at the sites nowadays. In the ERD $/ \gamma$ edition (Howse 2015b; Figure 5), however, Howse makes the transition from earth as soil to Earth as a planet. Instead of a dirt capsule, the module uses Pitchblende, the mineral used by Becquerel and Curie for their research on radioactivity. The manual-manifesto declares:

$\mathrm{ERD} / \gamma$ digs the Eurorack synth deep into geological time scales of radioactive decay. The module provides a radioactive source (Uraninite aka. Pitchblende), Geiger counter and processing to deliver both pure random voltages and random timing/triggers. Given the 
half life of the isotopes within the active material (Uranium-238 and Uranium-235) the module must be returned for recalibration in perhaps a few billion years. (Howse 2015b, p. 1)

The conventional temporality of the 'user's guide' is to make things work (again) and to prevent their damage in the near future. In the paper manual age, there used to be a suspended temporality of the lost manual which would halt all further action. Yet the digital manual cannot get lost anymore. As Howse projects the user guide's temporality onto the scale of the planet, the time of the manual gets out of hand. Quite nonchalantly, the text omits that in 'a few billion years' there will be most likely no extremities left that the manual might come in handy for. What is more, Howse's fiction of a 'deep obsolescence' is based upon the assumption that the other components have no regular obsolescence. Ezra Teboul has described Howse's instruments as 'post-optimal objects' (Teboul 2017, p. 111), referring to Anthony Dunne's proclamation of new poetic experiences through post-functional forms of design (Dunne 2005, p. 20).

\section{Conclusion}

This case study aimed to find non-human temporalities not in lyrics, artistic statements or self-fashioning, but in the non-human actors of popular music and the affordances they are provided by their creators. I looked at two pivotal instruments in popular music, the electric guitar and the synthesiser, not asking how they sound or what is played on them but how long they are supposed to produce musical information and which materials are used for this. Making music in the Anthropocene - in the sense of this study - is less about musical creation but (a) about recycling and transformation of material resources into cultural products and (b) the feedback processes between natural and industrially processed material and music. An attempt to only look at the literal geological material musical instruments employ is bound to fail - as non-human time necessarily requires figurative speech (Gould 1987, p. 3). For an inquiry of infinite sustain and radioactive decay as musical matters, metaphors provided a scope that transcends musical time towards deep time.

\section{References}

Bloland, P. 2007. 'The electromagnetically prepared piano and its compositional implications' in Proceedings of the 2007 International Computer Music Conference, Copenhagen (pp. 125-8)

Chakrabarty, D. 2018. 'Anthropocene time', History and Theory, 57/1, pp. 5-32

Devine, K. 2015. 'Decomposed: a political ecology of music', Popular Music, 34/3, pp. 367-89

Dunne, A. 2005. Hertzian Tales: Electronic Products, Aesthetic Experience, and Critical Design (Cambridge, MA, MIT Press)

Du Pisani, J. 2006. 'Sustainable development - historical roots of the concept', Environmental Sciences, 3/2, pp. 83-96

Eliade, M. 1978. The Forge and the Crucible (Chicago, IL, Chicago University Press)

Gould, S. 1987. Time's Arrow, Time's Cycle. Myth and Metaphor in the Discovery of Geological Time (Cambridge, MA, Harvard University Press)

Guitar Player, February 1986 (Saratoga NY, Guitar Players International)

Guitar Player, June 1989 (Saratoga NY, Guitar Players International)

Hoffmann, E.T.A. 1989[1820]: 'Casual reflections on the appearance of this journal' (Allgemeine Zeitung fur Musik und Musikliteratur), 9 and 16 October 1820, in E. T. A. Hoffmann's Musical Writings, ed., annotated and introduced by D. Charlton (Cambridge, Cambridge University Press), pp. 423-31

Howse, M. 2015a. ERD/ERD Manual - Raven Edition. http://1010.co.uk/org/erderdraven.pdf

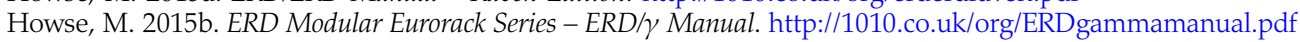


Howse, M. 2019. ERD Modular Eurorack Series 2019. http://1010.co.uk/org/ERD.html. http://1010.co.uk/org/ ERDgammamanual.pdf

Idezem 2018. Berlin Wall Distortion, YouTube video, January 23. https://www.youtube.com/watch? $\mathrm{v}=\mathrm{qzKSyllcCwc}$

Kahn, D. 2013. Earth Sound, Earth Signal: Energies and Earth Magnitude in the Arts (Berkeley, CA, California University Press)

Kahn, D. 2014. 'Epiphanies', The Wire, 359, January 2014, p. 106

Kittler F. 1997[1982]. 'Dracula's legacy', in Kittler F. Literature, Media, Information Systems: Essays, ed. J. Johnston (New York, Psychology Press), pp. 50-84

Latour, M. 2018. 'Santana and the metaphysics of tone: feedback loops, volume knobs, and the quest for transcendence', in The Relentless Pursuit of Tone: Timbre in Popular Music, ed. R. Fink, M. Latour and Z. Wallmark (New York, Oxford University Press)

LeMenager, S. 2014. Living Oil: Petroleum Culture in the American Century (Oxford, Oxford University Press)

Mavridis, N. 2010. 'Chandler germanium compressor test: Elementar-Teilchen', in Bonedo, 22 May. https:// www.bonedo.de/artikel/einzelansicht/chandler-germanium-compressor.html

McCarthy, T. 2015. Satin Island: A Novel (New York, Alfred A. Knopf)

Moog Music Inc. 2009. The Moog Guitar User's Guide

Morton, T. 2016. Dark Ecology (New York, Columbia University Press)

Nabokov, V. 1951. Speak, Memory. A Memoir (London, Gollancz)

Nolan, T., and Obrecht, J. 1985. 'The Edge', Guitar Player, June 1985, pp. 55-68; 89

Parikka, J. 2015. A Geology of Media (Minneapolis, MN, University of Minnesota Press)

Partridge, C. 2015. Mortality and Music: Popular Music and the Awareness of Death (London, Bloomsbury Academic)

Pigtronix 2017. 'Philosopher's tone micro'. https://pigtronix.com/product/philosophers-tone-micro/5/

Power, M. 2011. Hot Wired Guitar: The Life of Jeff Beck (New York, Omnibus Press)

Ribot, M. 2000. 'Earplugs', in Arcana: Musicians on Music. ed. J. Zorn (New York, Granary) pp. 233-7

Smith, J. 2015. Eco-sonic Media (Berkeley, CA, University of California Press)

Smithson, R. 1996. Collected writings, ed. J. Flam (Berkeley, Los Angeles, London, University of California Press)

Stoker, B. 1983[1897]. Dracula (Oxford, Oxford University Press)

Teboul, E. 2017. 'The transgressive practices of silicon luthiers', in Guide to Unconventional Computing for Music, ed. E.R. Miranda (Cham, Springer), pp. 85-120

The London Psychogeophysics Summit. 2010. 'What is psychogeophysics?', Mute, 4 August. http://www.metamute.org/community/your-posts/what-psychogeophysics

Walser, R. 1993. Running with the Devil: Power, Gender and Madness in Heavy Metal Music (Hanover, CT, Wesleyan University Press)

Watkins, H. 2011. Metaphors of Depth in German Musical Thought: From E. T. A. Hoffmann to Arnold Schoenberg (Cambridge, MA, Cambridge University Press)

Zielinski, S. 2006. Deep Time of the Media: Toward an Archaeology of Hearing and Seeing by Technical Means (Cambridge, MA MIT Press)

Ziolkowski, T. 2015. The Alchemist in Literature. From Dante to the Present (Oxford, Oxford University Press)

\section{Selected discography}

Beck, Jeff, Jeff Beck's Guitar Shop. Epic Records. 1989

Mitchell, Joni, Ladies of the Canyon. Reprise Records. 1970 